\title{
The Study of Micro Crack Plugging for Steam Stimulation Well
}

\author{
Liu $\mathrm{Yu}^{1, \mathrm{a}}$ \\ ${ }^{1}$ Petroleum Engineering Research Institute of Dagang Oilfield Company, Tianjin, 300280, China \\ anepuliuyu@126.com
}

\begin{abstract}
Keywords: Steam Stimulation; Micro Crack; Plugging; Fractal Theory
Abstract. During steam stimulation, micro crack can lead to steam channeling and decrease steam ratio and quantity at the bottom. According to the theory of elastic mechanics and thermodynamics, the micro crack calculating model was established. Micro crack width increases with the increasing of injection steam temperature. On this basis, select the bridge plugging material as micro crack plugging material. Basing on fractal theory, optimization model of plugging material was established. According to case study, the micro crack width increases with the increasing of injection steam temperature. When the steam temperature is $330^{\circ} \mathrm{C}$, the mass ratio of cement, micro-silicon and sand is 100:14.23:35.79. This study will provide the theoretical basis for micro crack plugging in steam stimulation wells, and provide technical guarantee for improving steam stimulation effectiveness.
\end{abstract}

\section{Introduction}

Steam stimulation is one of the effective method for developing heavy oil reservoir. In the process of steam stimulation, casing, cement sheath and borehole wall will expand because of thermality. Due to the different expansion rate, casing squeezes cement sheath, and cement sheath squeezes formation at the radial direction. When the well is shut in, due to the decreasing temperature, casing, cement sheath and borehole wall will shrink. Because of the different shrinking rate, the micro crack will create at the bonding face between casing and cement sheath, which will lead to steam channeling. The steam ratio and the quantity at the bottom will drop, and the steam stimulation effect will decrease. The study on micro crack plugging research was conducted, which can provide technical guarantee for improving steam stimulation effects.

\section{The Model for Calculating Micro Crack between Casing and Cement Sheath}

It is considered that casing is isotropy, and thermal expansion coefficient $(\alpha)$ is not changing with directions, and line strain is the same at all directions, and make the assumption that $\alpha$ is not changing with temperature. Thermal strain at points in the casing can be expressed as follow.

$$
\varepsilon_{\theta}=\varepsilon_{r}=\varepsilon_{z}=\alpha T
$$

According to the Lame's Formula, the radical stress $\left(\sigma_{r}\right)$ and circumferential stress $\left(\sigma_{\theta}\right)$ can be expressed as follow.

$$
\sigma_{r}=\frac{a^{2} p_{i}-b^{2} p_{0}}{b^{2}-a^{2}}-\frac{\left(p_{i}-p_{0}\right) a^{2} b^{2}}{\left(b^{2}-a^{2}\right) r^{2}} \quad \sigma_{\theta}=\frac{a^{2} p_{i}-b^{2} p_{0}}{b^{2}-a^{2}}+\frac{\left(p_{i}-p_{0}\right) a^{2} b^{2}}{\left(b^{2}-a^{2}\right) r^{2}}
$$

Where, $b$ and $a$ are outer and inner radius of thick wall cylinder, mm; $p_{\mathrm{i}}$ and $p_{0}$ are internal and external pressure respectively, $\mathrm{MPa} ; r$ is radius of force point that will be calculated, $\mathrm{mm}$.

The Eq. 1 can be simplified as follow. 


$$
\sigma_{r}=A / r^{2}+2 C \quad \sigma_{\theta}=-A / r^{2}+2 C
$$

The radial total stress is caused by pressure and temperature, and combining the the Lame's Formula and thermal expansion mechanical relationship, the Eq.4can be obtained.

$$
\sigma_{R}=\sigma_{r T}+\sigma_{r p}=-E \alpha \Delta T+A / r^{2}+2 C
$$

Combining pressure stress and temperature stress, according to generalized Hooke's Law, and adding the deformation caused by Eq.1, total deformation component can be expressed as follow.

$$
\left\{\begin{array}{l}
\varepsilon_{r}=1 / E^{*}\left[\sigma_{r}-\mu\left(\sigma_{\theta}+\sigma_{z}\right)\right]+\alpha \Delta T \\
\varepsilon_{\theta}=1 / E^{*}\left[\sigma_{\theta}-\mu\left(\sigma_{r}+\sigma_{z}\right)\right]+\alpha \Delta T \\
\varepsilon_{z}=1 / E^{*}\left[\sigma_{z}-\mu\left(\sigma_{\theta}+\sigma_{r}\right)\right]+\alpha \Delta T
\end{array}\right.
$$

Because the low temperature zone up the packer and the high temperature zone below the packer is false anchor section, the axial strain can be expressed as follow.

$$
\varepsilon_{z}=0 \quad \sigma_{z}=0
$$

Substituting Eq.6 into Eq.5, the Eq.7 is obtained.

$$
\varepsilon_{r}=\frac{1-\mu^{2}}{E}\left(\sigma_{r}-\frac{1-\mu}{\mu} \sigma_{\theta}\right)+(1+\mu) \alpha T
$$

According to the formula $(\Delta l=\varepsilon \times l)$, and combining Eq.3, Eq.7, the Eq.8 is obtained.

$$
D=\varepsilon_{r} \times r=\frac{1-\mu^{2}}{E}\left[\frac{1}{\mu} \times \frac{A}{r}+2 C r \times \frac{1+2 \mu}{\mu}\right]+(1+\mu) \alpha T r
$$

Boundary conditions: (1) when the pressure and temperature decrease, the micro crack will create and the contact force of casing outside wall is 0. Which can be expressed as Eq.9. (2) the pressure change of casing internal wall is always equal to the change of the casing pressure $\left(p_{\mathrm{a}}\right)$. The boundary condition of the casing internal wall can be expressed as Eq.10.

$$
\begin{gathered}
\left.\sigma_{r}\right|_{r=b}=0 \\
\left.\sigma_{r}\right|_{r=a}=p_{a}
\end{gathered}
$$

Substituting Eq.9 and Eq.10 into Eq.8, the Eq.11 is obtained.

$$
D=\frac{1-\mu^{2}}{E}\left[\frac{1}{\mu} \times \frac{a^{2} b^{2} p_{a}}{r\left(b^{2}-a^{2}\right)}+\left(\frac{a^{2} p_{a}}{a^{2}-b^{2}}+E \alpha \Delta T\right) r \times \frac{1+2 \mu}{\mu}\right]+(1+\mu) \alpha T r
$$

\section{The Study of Micro Crack Plugging}

A lot of material can be used to plug micro crack. According to the mechanism, six categories can be divided. They are bridge plugging material, high dehydration plugging material, temporary plugging material, chemical plugging material, inorganic gelling plugging material and soft (hard) plug plugging material. According to the actual situation of the micro crack plugging in steam stimulation well, the bridge plugging material is selected to prevent steam from channeling.

The Selection of Bridge Plugging Material. The bridge plugging material can be divided into three types: bridging particles, packing particles and deformation particles. 
The bridge particles can jam the channel's "throat" in the process of plugging, and has the effects of bridging. It is also called "bridging agent". Sand is used as bridging particle material. The sand has ability of anti-pressure, and it is invariant in the high temperature environment, and has no chemical reaction with the cement slurry.

The packing particles are suspended in the plugging fluid and are crisscrossed in the plugging, which is also known as the "suspension bracing agent". The cement particles are chosen as the packing particle material. Cement has the properties of low strength, high compressibility and low permeability. The cement can be filled in the pore space packed by sand particles forming the second packing structure.

The deformation particles have the effects of deformation, softening and packing in the plugging process, and it is also known as the "filling agent". Micro-silicon is used as the deformation material. The micro-silicon particles with unique physical and chemical properties can form the third filling structure.

Plugging Material Optimization Basing on Fractal Theory. As a kind of mine rock mass, the size distribution of plugging material particles has fractal characteristics. The fractal features of plugging material was studied, and the selection method of various particles in the combination plugging material is obtained. According to the concept of box dimensionality in fractal theory, assuming that particle size distribution is continuous, the fractal model construction expression (Eq.12) for the size distribution of plugging particle can be obtained.

$$
P(<d)=\left(d / d_{\max }\right)^{3-D}
$$

Where, $P(<d)$ is accumulate particle volume probability that the diameter is less than $d$.

According to the fractal value of micro crack width distribution, the plugging particles with same or similar particle distribution fractal value are selected as the optimized material for plugging micro crack. Basing on the thought, the optimization procedure for micro crack plugging material can be described as follow.

(1) Obtaining the relationship between power spectral density and spatial frequency of the crack width, using the fractal model of crack width distribution, the fractal value $\left(D_{1}\right)$ of crack width distribution and average pore radius of the crack can be calculated.

(2) According to the "2/3 bridge rule", the mean diameter of the stiff particles in plugging material can be obtained.

(3) According to the filling rules of $1 / 3 \sim 1 / 4$, the average particle diameter of packing and deformation particles can be determined

(4) Using the fractal model of particle size distribution, the fractal dimension of various plugging particles can be obtained.

(5) Combining the primary selected plugging materials with various proportion.

(6) Measure the fractal dimension $\left(D_{2}\right)$ of the combined particles size distribution.

(7) Choose the combined formula with the fractal dimension $D_{2}$ as the optimized plugging formula, which is most similar with $D_{1}$.

\section{Case Study}

Reservoir A is ordinary heavy oil reservoir located in normal pressure and temperature system. Viscosity of dead oil on the ground at formation temperature $\left(48.9^{\circ} \mathrm{C}\right)$ is $2300 \mathrm{mPa} \cdot \mathrm{s}$. Viscosity of gas-bearing oil at formation temperature is $156 \mathrm{mPa} \cdot \mathrm{s}$. Steel grade of casing is N80, outer diameter $177.8 \mathrm{~mm}$, wall thickness $8.05 \mathrm{~mm}$, well depth: $1400 \mathrm{~m}$. The pressure of injecting steam 
$\left(P_{\mathrm{s}}\right)$ is $10 \mathrm{MPa}$, steam ratio $\left(X_{\mathrm{s}}\right)$ 0.7, injection rate $\left(Q_{\mathrm{s}}\right) 8.0 \mathrm{t} / \mathrm{h}$, crack fractal dimension 2.556 . Cement, sand and micro-silicon are used as the raw material for plugging. The density of cement, sand and micro-silicon is $3.10 \mathrm{~g} / \mathrm{cm}^{3}, 2.65 \mathrm{~g} / \mathrm{cm}^{3}, 2.60 \mathrm{~g} / \mathrm{cm}^{3}$ respectively. According to the model, the crack width at different injection temperature is obtained, which is shown in Tab.1.

Tab.1 The crack width table at different steam injection temperature

\begin{tabular}{|c|c|c|c|c|c|c|}
\hline $\begin{array}{c}\text { Injection Temperature } \\
{ }^{\circ} \mathrm{C}\end{array}$ & 300 & 310 & 320 & 330 & 340 & 350 \\
\hline $\begin{array}{c}\text { Crack Width } \\
\mu \mathrm{m}\end{array}$ & 99.60 & 124.00 & 148.10 & 172.20 & 196.30 & 220.40 \\
\hline
\end{tabular}

It can be seen from Tab. 1 that the crack width is $172.20 \mu \mathrm{m}$ under $330^{\circ} \mathrm{C}$ injection temperature. The designed matching ratio of sand, cement and micro-silicon can be described as follow. The average particle diameter of sand is $114.80 \mu \mathrm{m}$, and the particle volume ratio with the diameter of $92.05-137.91 \mu \mathrm{m}$ is $91 \%$. The average particle diameter of cement is $57.40 \mu \mathrm{m}$, and the particle volume ratio with the diameter of $1.45-102.18 \mu \mathrm{m}$ is $98 \%$. The average particle diameter of micro-silicon is $0.14 \mu \mathrm{m}$, and the particle volume ratio with the diameter of $0.02-1.58 \mu \mathrm{m}$ is $98 \%$. After mass conversion, the mass ratio of cement, micro-silicon and sand is 100:14.23:35.79.

Tab.2 The volume fraction table of the three particles

\begin{tabular}{|c|c|c|c|c|c|c|c|c|}
\hline $\begin{array}{c}\text { Distribution Range } \\
\text { of Particle Diameter } \\
\mu \mathrm{m}\end{array}$ & 0.14 & 1.45 & 1.58 & 57.40 & 92.05 & 102.18 & 114.80 & 137.91 \\
\hline $\begin{array}{c}\text { Volume Fraction } \\
\text { of Particle } \\
\%\end{array}$ & 3.94 & 11.11 & 11.55 & 56.91 & 70.18 & 73.51 & 77.41 & 83.98 \\
\hline
\end{tabular}

\section{Conclusions}

1. According to the theory of elastic mechanics and thermodynamics, the micro crack calculating model between casing and cement sheath for heavy oil steam stimulation wells was obtained. The micro crack width at different injection temperature was calculated, and the micro crack width increases with the increasing of injection steam temperature.

2. The material for plugging micro crack includes bridging particles, packing particles and deformation particles. The optimization model of plugging material was established basing on fractal theory, the particle size distribution and proportion of different particles was obtained.

3. A steam stimulation well micro crack plugging calculation was conducted by using the model, and the width of crack at different steam temperature was obtained. When the steam temperature is $330^{\circ} \mathrm{C}$, the mass ratio of cement, micro-silicon and sand is 100:14.23:35.79.

\section{References}

[1] Cui Xiaobing, Cao Ling, Zhang Hong, et al. New Development of the Study on Casing Failure Mechanism for the Production Wells Stimulated with Steam Injection[J]. Journal of China University of Petroleum, 1997, 21(03): 59-66+119-120.

[2] Zhao Xiutai, Fu Minjie, et al. Research overview of profile control and water shut-off agents for heavy oil thermal recovery[J]. Special Oil \& Gas Reservoirs, 2013, 20(04):1-4+151.

[3] Yu Chengjin, Li Chenglin. Calculation of micro annulus between casing and cement shealth[J]. Petroleum Drilling Techniques, 1996, 24(04): 34-35+38+64.

[4] Chen Yong, Lian Zhanghua, et al. Analysis of borehole thermal stress for thermal recovery well with micro crack at the first interface[J]. China Petroleum Machinery, 2008, 6(01):7-10.

[5] Yang Guitong. Elastic Mechanics[M]. Beijing: Higher Education Press, 2001. 
[6] Yang Yong. Academic research on plugging micro-clearance for gas blocking of gas well [D]. Daqing Petroleum Institute, 2008.

[7] Zhao Xinwei, Xu Hong. Micro focus X-CT based fine characterization of carbonate pore texture[J]. Special Oil \& Gas Reservoirs, 2016, 23(01): 127-131+157. 